\title{
QUALIDADE MICROBIOLÓGICA DA ÁGUA UTILIZADA EM FAZENDAS LEITEIRAS PARA LIMPEZA DAS TETAS DE VACAS E EQUIPAMENTOS LEITEIROS EM TRÊS MUNICÍPIOS DO ESTADO DO MARANHÃO
}

\author{
L.M. Lacerda1 ${ }^{1}$ R.A. Mota ${ }^{2}$, M.J. Sena² \\ ${ }^{1}$ Universidade Estadual do Maranhão, Cidade Universitária “Paulo XVI", Tirirical, s/no, CEP 65000-000, São \\ Luis, MA, Brasil. lenkalacerda@yahoo.com.br
}

\begin{abstract}
RESUMO
Objetivou-se com este estudo avaliar a qualidade da água utilizada na higienização do úbere dos animais, de equipamentos e utensílios de ordenha em propriedades leiteiras nos municípios de Miranda do Norte, Itapecurú-Mirim e Santa Rita, MA, através do NMP de coliformes totais e Escherichia coli, pelo método Colilert. Foram coletadas 20 amostras de água no período de verão (agosto a dezembro/2006) e 20 amostras no período de inverno (janeiro a julho/2007). Verificouse no verão que coliformes totais variaram de ausência a contaminação máxima tabelada (> 2419,6 NMP) e E. coli variou de ausência a 344,1 NMP e no inverno, coliformes totais variaram de ausência a contaminação máxima (> 2419,6 NMP) e E. coli variou de ausência a 770,1 NMP. No verão, 90\% das amostras para coliformes totais e $75 \%$ de amostras para $E$. coli e no inverno, $90 \%$ das amostras para coliformes totais e $70 \%$ para $E$. coli estavam em desacordo com a portaria $n^{\circ} 518 / 2004$ do Ministério da Saúde. É necessária a realização de um trabalho de educação sanitária junto à população do meio rural, a adoção de medidas preventivas, visando minimizar a ocorrência de enfermidades de veiculação hídrica, e melhoria da qualidade do leite produzido nas propriedades leiteiras.
\end{abstract}

PALAVRAS-CHAVE: Água, coliformes total, E. coli, Colilert.

\section{ABSTRACT}

MICROBIOLOGICAL QUALITY OF WATER USED ON DAIRY FARMS FOR THE CLEANING OFCOWTEATSANDMILKINGEQUIPMENT INTHREETOWNSOFTHESTATEOFMARANHÃO, BRAZIL. The present study was aimed at evaluating the quality of the water used for the cleaning of dairy-cow teats and milking equipment on dairy farms located in the counties of Miranda do Norte, Itapecurú-Mirim and Santa Rita, in Maranhão State, Brazil, by using the MPN (most probably number) technique in the enumeration of total coliforms and Escherichia coli, according to the Colilert method. Samples of water were taken during summertime (August through December 2006, 20 samples) and wintertime (January through July 2007, 20 samples). Analysis showed that, in summertime, total coliforms ranged from absent to maximum contamination (> 2419.6 NMP) while E. coli ranged from absent to $344.1 \mathrm{NMP}$, and that, during wintertime, total coliforms ranged from absent to maximum contamination (>2419.6 NMP) while E. coli ranged from absent to 770.1 NMP. During summertime, $90 \%$ and $75 \%$ of samples did not meet the requirements of the Brazilian Health Ministry regulation 518/2004 for total coliforms and E. coli, respectively. The same percentages in wintertime were $90 \%$ and $70 \%$. The results clearly indicate the need for a sanitary education effort involving the rural population, coupled with the implementation of preventive measures, in order to improve the quality of the milk produced in the facilities studied.

KEY WORDS: Water, microbiology, E. coli, Colilert.

\section{INTRODUÇÃO}

A água é considerada um dos elementos fundamentais para a existência do homem. Suas funções no abastecimento público, industrial e agropecuário, na preservação da vida aquática, na recreação eno transporte demonstram essa importância vital (GUILHERME et al., 2000).

\footnotetext{
${ }^{2}$ Universidade Federal Rural de Pernambuco, Recife, PE, Brasil.
} 
Aliadas à falta de água potável estão a má distribuição e contaminação do recurso hídrico. Atualmente cerca de 1,4 bilhões de pessoas não têm acesso à água limpa e a cada oito segundos, morre uma criança por uma doença relacionada com água contaminada como disenteria e cólera. Cerca de $80 \%$ das enfermidades no mundo são contraídas devido à água poluída (Leite et al., 2003).

BARCELlos et al. (2006) estudaram a qualidade da água na zona rural de Lavras, MG, e observaram contaminação fecal nos mananciais, inclusive os subterrâneos e subsuperficiais. Enfatizaram a necessidade da busca de conhecimentos da realidade sanitária no meio rural, caracterizada por populações com menor acesso às medidas de saneamento, e pela presença de atividades agropecuárias altamente impactantes, podendo interferir na qualidade da água dos mananciais que abastecem a área urbana.

Segundo Ribeiro et al. (2000), a água utilizada no ambiente de ordenha para limpeza, tanto dos tetos dos animais como dos equipamentos de ordenha (coletores, ordenhadeiras mecânicas, baldes etc.), pode atuar como via de transmissão de micro-organismos para a glândula mamária, bem como comprometer a qualidade do leite, uma vez que a água com alta contagem de bactérias, utilizada na limpeza dos equipamentos, possibilita a veiculação da população bacteriana diretamente para o leite quando este entra em contato com as superfícies contaminadas.

Embora seja evidente a importância que a água exerce sobre a qualidade do leite, poucos produtores e indústrias de laticínios têm monitorado a qualidade da água. Pode-se dizer que, seguramente, a baixa qualidade da água é um dos aspectos mais importantes que contribui para a produção de leite com alta contagem bacteriana total (CBT) (CERQUEIRA et al., 2006).

Enfatizando a importância da qualidade da água e a ausência de pesquisas na literatura regional sobre o tema abordado, realizou-se este estudo, objetivando subsidiar a avaliação da qualidade da água utilizada na higienização do úbere dos animais, equipamentos e utensílios de ordenha em propriedades leiteiras nos municípios de Miranda do Norte, Itapecurú-Mirim e Santa Rita, Estado do Maranhão.

\section{MATERIAL E MÉTODOS}

Para determinação da qualidade da água foram selecionadas, não probabilisticamente por conveniência, 20 propriedades produtoras de leite, localizadas nos municípios de Miranda do Norte, ItapecurúMirim e Santa Rita, Estado do Maranhão, representando pequenos, médios e grandes produtores, com ordenha manual e mecânica, durante o período de verão (agosto a dezembro de 2006) e inverno (janeiro a julho de 2007).

A colheita da água foi realizada assepticamente nos pontos de saída (torneiras) localizadas na sala de ordenha das propriedades visitadas e, em seguida, acondicionadas em bolsas de polietileno (Thio-bag) contend o thiosulfato de sódio nas amostras de rede de distribuição e encaminhadas em caixas isotérmicas contendo gelo reciclável, ao Laboratório de Microbiologia de Alimentos da Universidade Estadual do Maranhão (UEMA), onde foram submetidas às análises de pesquisa de coliformes totais e E. coli por meio do método rápido - Colilert (Tecnologia de substrato definido - IDEXX).

Durante as colheitas das amostras foram aplicados questionários investigativos, contendo questões fechadas, visando determinar a origem da água; tratamento dadoàágua; tipo de resíduos encontrados na água; a distância entre a fonte da água e fossas sépticas, lagoas, esterqueiras e currais; se a fonte de água está na parte mais elevada do terreno; qual o estado de conservação da fonte, se já efetuou limpeza da caixa d'água; frequência de problemas gastrointestinais (diarreia/vômitos) entre os moradores da comunidade; qual a opinião sobre a água da propriedade; se realizou alguma análise da água; frequência de vezes que a água foi analisada e qual o resultado obtido sobre a qualidade dessa análise.

Foi adicionado o reagente (ONPG e MUG) em 100 mL de água e após uma homogeneização, a amostra foi despejada na cartela Quanti-Tray para quantificação de coliformes totais e E. coli; em seguida a cartela foi lacrada e incubada por 24 horas a $35^{\circ} \mathrm{C}$.

Os resultados foram verificados com a mudança de cor nas cavidades da cartela para amarelo nas amostras positivas para coliformes totais e paraE.coli as cavidades amarelas fluorescentes eram consideradas positivas na presença de luz UV de $365 \mathrm{~nm}$. Contavam-se as cavidades positivas e comparava-se com uma tabela para Número Mais Provável - NMP.

Para a análise dos dados foram obtidas as distribuições absolutas, percentuais e as medidas estatísticas: média, mediana, desvio padrão, coeficiente de variação, valor mínimo e máximo e o valor de correlação de Pearson (técnicas de estatística descritiva) e teste de Wilcoxon de Postos Sinalizados (Altman; HALL, 1991; ZAR, 1999).

\section{RESULTADOS E DISCUSSÃO}

Na Tabela 1 verifica-se queem $40 \%$ das propriedades estudadas a água utilizada era proveniente de açude, $40 \%$ de poços artesianos, $10 \%$ de poços cacimbas e $10 \%$ de rede de distribuição. Na maioria das 
propriedades (85\%) nãosefazia o tratamento daágua e os tipos de resíduos encontrados nela eram 15\% turvações, $15 \%$ partículas suspensas, $15 \%$ turvações e partículas suspensas, $10 \%$ presença de limo vermelho e $45 \%$ dos proprietários afirmavam que nunca observaram resíduos. Quando foram questionados se a fonte de água está situada a mais de $30 \mathrm{~m}$ de distância de fossas sépticas, lagoas, esterqueiras e currais, $85 \%$ afirmaram que sim, enquanto $80 \%$ dos proprietários afirmaram que a fonte de água está situada na parte mais elevada do terreno e $20 \%$ dos proprietários consideram ótimo, $55 \%$ bome $25 \%$ ruim o estado da fonte da água utilizada nas propriedades leiteiras.

$\mathrm{Na}$ Tabela 2, estão apresentados os resultados referentes ao armazenamento da água utilizada no processo de ordenha, sendo que apenas $40 \%$ dos proprietários afirmaram que já efetuarama limpeza da caixa d'água e a frequência de limpeza era de uma (5\%), duas (15\%) e mais de três vezes (20\%). Quando foram questionados sobre a frequência de problemas gastrointestinais (diarreia/vômito) entre os moradores da comunidade, $10 \%$ afirmaram que nunca tiveram problemas e $90 \%$ não souberam responder. Apenas 30\% dos proprietários afirmaram que a água era ótima, $40 \%$ a consideravam boa e $30 \%$ regular, mas apenas $20 \%$ realizaram análise da água, sendo que $20 \%$ realizaram essa análise apenas uma vez. Desses 20\% que realizaram análise, 5\% afirmaram que os resultados confirmaram que a água era de ótima qualidade, $10 \%$ que a água era boa e $5 \%$ não souberam informar.

Em um estudo realizado por PICININ (2003) em propriedades leiteiras de Minas Gerais, 100\% das propriedades que possuíam como origem mina, cisterna, ou riacho, apresentaram amostras de água impróprias ao consumo e outros fins, ou seja, a água não apresentava nenhum grau de potabilidade e nas propriedades que possuíam poço ou rede de distribuição, apresentaram 42,86\% e 50,00\% de água considerada potável e de boa qualidade, respectivamente. No entanto, os resultados estavam em desacordo com relação à distância da fonte de abastecimento em relação aos locais de contaminação, onde se observou apenas $21,88 \%$ das propriedadescom distância mínina de $30 \mathrm{~m}$ de local de risco de contaminação e 50,00\% dos entrevistados afirmaram que faziam mais de três limpezas de caixas d'águas por ano.

Apesar de não existir padrões específicos para a água empregada no processo de obtenção do leite, Robinson (1987) afirma ser necessário que este produto apresente características bacteriológicas semelhantes às da água potável, ou seja, ausência de coliformes totais eE. coli em $100 \mathrm{~mL}$ de água, segundo a portaria $n^{\circ} 518 / 2004$ do Ministério da Saúde.
Tabela 1 - Distribuição das propriedades leiteiras analisadas segundo as variáveis relativas à água utilizada no processo de ordenha nas propriedades leiteiras de Miranda do Norte, Itapecurú-Mirim e Santa Rita, MA.

\begin{tabular}{lrr}
\hline Variável & $\mathrm{n}$ & $\%$ \\
\hline • Origem da água & & \\
Açude & 8 & 40,0 \\
Poço artesiano & 8 & 40,0 \\
Poço cacimba & 2 & 10,0 \\
Rede de distribuição & 2 & 10,0 \\
Total & 20 & 100,0 \\
- Tratamento da água & \multicolumn{2}{c}{} \\
Sim & 3 & 15,0 \\
Não & 17 & 85,0 \\
Total & 20 & 100,0 \\
- Tipo de resíduos encontrados na água analisada & \\
Turvações & 3 & 15,0 \\
Partículas suspensas & 3 & 15,0 \\
Partículas suspensas / turvações & 3 & 15,0 \\
Presença de limo vermelho & 2 & 10,0 \\
Nunca observou & 9 & 45,0 \\
Total & 20 & 100,0
\end{tabular}

- A fonte da água está situada a mais de $30 \mathrm{~m}$ de distância de fossas sépticas, lagoas, esterqueiras, currais

$\begin{array}{lrr}\text { Sim } & 17 & 85,0 \\ \text { Não } & 3 & 15,0 \\ \text { Total } & 20 & 100,0\end{array}$

- Fonte da água está situada na parte mais elevada do terreno

\begin{tabular}{lrr} 
Sim & 16 & 80,0 \\
Não & 4 & 20,0 \\
Total & 20 & 100,0 \\
• Qual o estado de conservação da fonte & & \\
Ótimo & 4 & 20,0 \\
Bom & 11 & 55,0 \\
Ruim & 5 & 25,0 \\
Total & 20 & 100,0 \\
\hline
\end{tabular}

Resultados semelhantes aos obtidos neste estudo foram observados por Polegato; Amaral (2005) em propriedades leiteiras do Município de Marília, SP, onde $90 \%$ das propriedades não efetuavam tratamento químico da água e nunca analisaram a água que consomem e $10 \%$ que tratavam a água o faziam de maneira inadequada.

Devido a situações como estas, a baixa qualidade microbiológica da água utilizada nas fazendas indica a necessidade de mais pesquisas e adoção de medidas corretivas, devido aos riscos de contaminação do leite, afetando consideravelmente sua qualidade final.

Na Tabela 3 estão descritos os resultados das análises microbiológicas da água utilizada no processo deordenha no período de verão, ondecoliformes 
totais variaram de ausência à contaminação máxima tabelada (> 2419,6 NMP) e E. coli variaram de ausência a 344,1 NMP. Portanto, 90\% das amostras para coliformes totais e $75 \%$ de amostras para E. coli estavam em desacordo com a portaria ${ }^{\circ} 518$ do Ministério da Saúde que cita ausência de coliformes e E. coli em 100 mL de água potável.

Tabela 2 - Distribuição das propriedades leiteiras analisadas segundo as variáveis relativas ao estado de armazenamento da água utilizada no processo de ordenha nas propriedades leiteiras de Miranda do Norte, Itapecurú-Mirim e Santa Rita, MA.

\begin{tabular}{|c|c|c|}
\hline Variável & $\mathrm{n}$ & $\%$ \\
\hline \multicolumn{3}{|c|}{ - Já efetuou limpeza da caixa d'água? } \\
\hline Sim & 8 & 40,0 \\
\hline Não & 12 & 60,0 \\
\hline Total & 20 & 100,0 \\
\hline \multicolumn{3}{|c|}{ - Frequência de limpeza da caixa d'água } \\
\hline Uma & 1 & 5,0 \\
\hline Duas & 3 & 15,0 \\
\hline Mais de três & 4 & 20,0 \\
\hline Nunca efetuou limpeza & 12 & 60,0 \\
\hline Total & 20 & 100,0 \\
\hline \multicolumn{3}{|c|}{$\begin{array}{l}\text { - Frequência de problemas gastrointestinais (diarreia/ } \\
\text { vômitos) Entre os moradores da comunidade }\end{array}$} \\
\hline Não & 2 & 10,0 \\
\hline Não sabe & 18 & 90,0 \\
\hline Total & 20 & 100,0 \\
\hline \multicolumn{3}{|c|}{ • Qual a sua opinião sobre a água da propriedade? } \\
\hline Ótima & 6 & 30,0 \\
\hline Boa & 8 & 40,0 \\
\hline Regular & 6 & 30,0 \\
\hline Total & 20 & 100,0 \\
\hline \multicolumn{3}{|c|}{ - Realizou alguma análise da água da propriedade } \\
\hline Sim & 4 & 20,0 \\
\hline Não & 16 & 80,0 \\
\hline Total & 20 & 100,0 \\
\hline \multicolumn{3}{|c|}{ - Frequência de vezes que a água foi analisada } \\
\hline Uma vez & 4 & 20,0 \\
\hline Não realizou análise & 16 & 80,0 \\
\hline Total & 20 & 100,0 \\
\hline \multicolumn{3}{|c|}{$\begin{array}{l}\text { - Qual o resultado obtido sobre a qualidade da água } \\
\text { analisada? }\end{array}$} \\
\hline Ótimo & 1 & 5,0 \\
\hline Bom & 2 & 10,0 \\
\hline Não sabe informar & 1 & 5,0 \\
\hline Não realizou análise & 16 & 80,0 \\
\hline Total & 20 & 100,0 \\
\hline
\end{tabular}

Giatti(2007), utilizando a mesma metodologia do presente trabalho, evidenciou em 65 amostras de água deáreas indígenas deSão Gabriel da Cachoeira, $\mathrm{AM}$, que $89,2 \%$ delas apresentaram coliformes termotolerantes.

Na Tabela 4 observam-se os resultados de análises microbiológicas da água utilizada no processo de ordenha no período do inverno, onde coliformes totais variaram de ausênciaà contaminação máxima (>2419,6 NMP) e E. coli variou de ausência a 770,1 NMP, sendo que $90 \%$ das amostras de coliformes totais e $70 \%$ das amostras de E. coli estavam em desacordo com a portaria $n^{0}$ 518/2004 MS, para água potável.

Tabela 3 Resultado de análises microbiológicas da água utilizada no processo de ordenha nas propriedades leiteiras de Miranda do Norte, Itapecurú-Mirim e Santa Rita MA, durante o período do verão.

\begin{tabular}{ccc}
\hline Amostras & Coliformes Total/NMP & Escherichia coli \\
\hline 1 & $1.119,9$ & 46,5 \\
2 & $1.046,3$ & 23,5 \\
3 & 648,8 & 3 \\
4 & 2 & $<1$ \\
5 & 13,1 & $<1$ \\
6 & $1.553,1$ & 1 \\
7 & 980,4 & 2 \\
8 & $2.419,6$ & 344,1 \\
9 & $>2.419,6$ & 13,1 \\
10 & $>2.419,6$ & 12 \\
11 & $>2.419,6$ & 13,1 \\
12 & $>2.419,6$ & 12 \\
13 & 14,6 & $<1$ \\
14 & 15,8 & 4,1 \\
15 & 648,8 & 13,5 \\
16 & 488,4 & 18,7 \\
17 & 517,2 & 204,6 \\
18 & 344,8 & 143 \\
19 & $<1$ & $<1$ \\
20 & $<1$ & $<1$ \\
\hline
\end{tabular}

Quando se comparou os valores médios dos NMP de coliformes totais e E. coli pelo teste de Wilcoxon com $p=5 \%$ de probabilidade, verificou-se que não há diferença significativa para níveis de contaminação no período de verão e inverno.

Os resultados obtidos no presente estudo foram similares aos verificados por RAPINI et al. (2003) em propriedades leiteiras da região metropolitana de Belo Horizonte, MG, onde $76,8 \%$ e $60,9 \%$ da água utilizada na limpeza de equipamentos e utensílios de ordenha apresentavam coliformes totais e coliformes termotolerantes, respectivamente. Enfatizando a importância do monitoramento da qualidade da água, evitando a contaminação do leite. 
Tabela 4 - Resultados de análises microbiológicas da água utilizada no processo de ordenha nas propriedades leiteiras de Miranda do Norte, Itapecurú-Mirim e Santa Rita, MA, durante o período do inverno.

\begin{tabular}{ccc}
\hline Amostras & Coliformes Total/NMP & Escherichia coli \\
\hline 1 & 1553,1 & 1 \\
2 & $>2.419,6$ & 15,5 \\
3 & $>2.419,6$ & $<1$ \\
4 & 2 & $<1$ \\
5 & $<1$ & $<1$ \\
6 & $>2.419,6$ & 19,1 \\
7 & $>2.419,6$ & 8,4 \\
8 & $2.419,6$ & 770,1 \\
9 & $>2.419,6$ & 727 \\
10 & 517,2 & 12,6 \\
11 & 435,2 & 11,3 \\
12 & 579,4 & 2 \\
13 & 5,2 & $<1$ \\
14 & 461,1 & 6 \\
15 & $>2.419,6$ & 308,8 \\
16 & 920,8 & 14,5 \\
17 & 25,9 & 23,1 \\
18 & 5,2 & $<1$ \\
19 & $<1$ & $<1$ \\
20 & 21,1 & 4,1 \\
\hline
\end{tabular}

Resultados satisfatórios foram verificados por Blanch et al. (2007) que observaram uma ocorrência de $2 \%$ de E. coli em 16.576 amostras de água de uma rede de distribuição na cidade de Barcelona, na Espanha.

Os achados do presente trabalho corroboram os de AMARAL et al. (2003) que estudaram a qualidade higiênico-sanitária de 180 amostras de águas de consumo humano em 30 propriedades rurais da região Nordeste deSãoPaulo. Os resultados evidenciaram que $90 \%$ das amostras deágua das fontes e dos reservatórios e 96,7\% de água de consumo humano quando colhidas no período de chuvas e $83,3 \%, 96,7 \%$ e $90 \%$ daquelas colhidas, respectivamente, nos mesmos locais, durantea estiagem, estavam fora dos padrões microbiológicos de potabilidade para água de consumo humano.

Os resultados obtidossãoinadequadose pioresaos observados por ComBARro et al. (1998) em 80 amostras deágua de poçona zona rural deGalicia no Chile, onde verificarama ocorrência decoliformes totais, coliformes termotolerantes e E. coli em $63,75 \%, 23,75 \%$ e $21,25 \%$ das amostras de água, respectivamente.

Na Tabela 5 estão apresentados os resultados das análises da água no período de verão e inverno. Não houvediferença na qualidademicrobiológica das amostras deágua entre os períodos do ano $(\mathrm{P}>0,05)$. A média noverãofoide974,66e42,96(NMP/mL) paracoliformes totais e E. coli,eno inverno a média foi de 1073,27 e 96,48 $(\mathrm{NMP} / \mathrm{mL})$ para coliformes totais e E. coli.

Os resultados foram inadequados no presente trabalho sendo semelhantes aos observados por RIBEIRO et al.(2000) que avaliaram 34 amostras de água utilizadas na ordenha de propriedades leiteiras dos estados de Minas Gerais e São Paulo e encontraram 75,55\% delas fora dos padrões paraágua potável, com média de $170 \mathrm{NMP} / 100 \mathrm{~mL}$ de água e variando de ausência a $16 \times 10^{3}$.

Resultados semelhantes aos obtidos neste estudo foram também observados por AMARAL et al.(2005) ao pesquisarem em água de consumo humano das fontes de abastecimento (poço e mina), reservatórios e pontos de consumo em 13 propriedades rurais produtoras de suíno na região Noroeste de São Paulo onde não houve diferença nas porcentagens de amostras fora dos padrões para E. coli entre os períodos de seca e chuva. Enfatizam ainda que a E. coli está presente na água sempre em decorrência do aporte de material fecal. Com relação aos coliformes totais, a maior ocorrência foi no período das chuvas nos reservatórios e no período da estiagem nas fontes de abastecimento.

Em um estudo sobre a qualidade microbiológica da água de propriedades rurais de Franca, SP,JACINTHO et al. (2005) verificaram resultados inadequados aos observados no presente trabalho, com 77,4\% das amostras fora dos padrões durante a estiagem e 70\% das amostras no período de chuvas. Concluem que são necessárias melhorias na qualidade sanitária da água das propriedades para prevenir doenças de transmissão hídrica, garantindo melhorias na qualidade de vida da população rural.

GARBOGgini; GALLO (1998), ao utilizarem o sistema Colilert para analisar a qualidade microbiológica de água denascentes (bicas) naárea urbana dePiracicaba, SP, verificaram que $100 \%$ das amostras estavam contaminadas por coliformes totais. Os mesmos autores relacionaram a época de maior precipitação pluviométrica com a positividade para E. coli, bem como negatividade em épocas sem chuva, o que leva a crer que essas nascentes talvez estejam sofrendo contaminação por meio das águas das chuvas.

A preocupação com a qualidade da água utilizada no processo de ordenha deve ser constante. MEDEIROS (2005) analisou a água utilizada na ordenha, limpeza dos tetos e ordenhadeiras, em propriedades leiteiras no Município de Cerqueira César, SP, e concluiu que $94 \%$ da água estava fora dos padrões de potabilidade e que aE. coli foi isolada em $51 \%$ das amostras deágua utilizada no processo de ordenha. Contudo, não foi observada associação entre os agentes encontrados na água utilizada no processo de ordenha com os agentes isolados no leite mastítico analisados nas mesmas propriedades. 
Tabela 5 - Estatística das variáveis: coliformes total e E. coli da água utilizada no processo de ordenha nas propriedades leiteiras de Miranda do Norte, Itapecurú-Mirim e Santa Rita, MA, segundo a estação do ano (verão e inverno).

\begin{tabular}{lllll}
\hline & \multicolumn{4}{c}{ Estação do ano } \\
\cline { 2 - 5 } Variável & Estatísticas & Verão & Inverno & Valor dep \\
\hline - Coliformes total $(\mathrm{NMP} / \mathrm{mL})$ & Média geométrica & 211,73 & 179,71 & $\mathrm{p}^{1}=0,679$ \\
& Mediana & 648,80 & 548,30 & \\
- E. coli $(\mathrm{NMP} / \mathrm{mL})$ & Média & 974,66 & 1073,27 & \\
& Desvio padrão & 958,69 & 1081,17 & $\mathrm{p}^{1}=0,877$ \\
& Média geométrica & 8,15 & 7,95 & 7,20 \\
\\
& Mediana & 12,00 & 96,48 & \\
\hline
\end{tabular}

${ }^{1}$ Através do teste de Wilcoxon de Postos Sinalizados para dados pareados.

A água utilizada no processo de obtenção do leite pode representar um risco em potencial tanto para o estado sanitário da glândula mamária como para a qualidade microbiológica do leite, quando não atende aos padrões de potabilidades para consumo humano.

\section{CONCLUSÃO}

A maioria da água utilizada na higienização do úbere dos animais, equipamentos e utensílios de ordenha em propriedades leiteiras nos municípios de Miranda do Norte, Itapecurú-MirimeSanta Rita, MA, está fora dos padrões microbiológicos para potabilidade, de acordo com a portaria $\mathrm{n}^{\circ}$ 518/2004 do Ministério da Saúde.

É necessária a realização de um trabalho de promoção em saúde junto à população do meio rural, a adoção de medidas preventivas e tratamento das águas comprometidas, visando minimizar a ocorrência de enfermidades de veiculação hídrica e melhoria da qualidade do leite produzido nas propriedades leiteiras.

Provavelmente as altas contagens de coliformes totais e E. coli encontradas na água das propriedades leiteiras estudadas sejam devido à disposição inadequada de resíduos orgânicos oriundos de atividades humana e animal, proporcionando contaminação nas fontes de captação e nas redes de distribuição, aliado à ausência de limpeza das caixas d'água e de tratamento químico e também pelo desconhecimento do produtor rural em relação ao risco à saúde decorrente do consumo de água contaminada. Os proprietários ainda acreditam que a água de poço, açude e rede de distribuição são de boa qualidade e, desta forma, existe um descaso em relação à adoção de medidas de prevenção da qualidade da água consumida.

\section{REFERÊNCIAS}

ALTMAN, D.G.; HALL, C. Practical Statistics for Medical Research. London: Chapman and Hall, 1991. 611p.

AMARAL, L.A.; NADER FILHO, A.; ROSSI JUNIOR, O.D.; FERREIRA, F.L.A.; BARROS, L.S.S. Água de consumo humano como fator de risco à saúde em propriedades rurais. Revista de Saúde Pública, v.37, n.4, p.510-514, 2003.

AMARAL, L.A.; ROSSI JR, O.D.; NADER FILHO, A.; SOUZA, M.C.I.; ISA, H. Água utilizada em suinocultura como fator de risco à saúde humana e animal. Ars Veterinária, v.21, n.1, p.41-46, 2005.

BARCELLOS, C.M.; ROCHA, M.; RODRIGUES, L.S.; COSTA, C.C.; OLIVEIRA, P.R.; SILVA, I.J.; JESUS, E.F.M.; ROLIM, R.G. Avaliação da qualidade da água e percepção higiênico-sanitária na área rural de Lavras, Minas Gerais, Brasil, 1999-2000. Cadernos de Saúde Pública, v.22, n.9, p.1967-1978, 2006.

BLANCH, A.R.; GALOFRÉ, B.; LUCENA, F.; TERRADILLOS, A.; VILANOVA, X.; RIBAS, F.

Characterization of bacterial coliform occurrences in different zones of drinking water distribution system. Journal do Applied Microbiology, v.102, n.3, p.711-721, 2007

CERQUEIRA, M.M.O.P.; PICININ, L.C.A.; FONSECA, L.M.; SOUZA; M.R. de.; LEITE, M.O. Qualidade da água e seu impacto na qualidade microbiológica do leite. In: CONGRESSO BRASILEIRO DE QUALIDADE DO LEITE, 2., 2006, Goiânia. Resumos. Goiânia, 2006.

COMBARRO, M.P.; LONGO, E.; AGRELO, D.; ARIAS, C.; PARDO, F.; VILLA, T.G.; GARRIDO, M.J.

Contaminación bacteriana em pozos de zonas rurales de Galicia. Revista de Sanidad Higiene Publica, v.62, p.1561-1569, 1988. 
GARBOGGINI, I.L.A.; GALLO, C.R. Pesquisa de Salmonella, Campylobacter, Coliformes totais e Escherichia coli em águas de nascentes (bicas) em Piracicaba, SP. In: CONGRESSO BRASILEIRO DE CIÊNCIA E TECNOLOGIA DE ALIMENTOS, 16., 1998, Rio de Janeiro. Resumos. Rio de Janeiro, 1998.

GIATTI, L.L. Reflexões sobre água de abastecimento e saúde pública: um estudo na amazônia brasileira. Revista Saúde e Sociedade, v.16, n.1, p.134-144, 2007.

GUILHERME, E.F.M.; SILVA, J.A.M.; OTTO, S.S.

Pseudomonas aeruginosa como indicador de contaminação hídrica. Higiene Alimentar, v.14, n.76, p.43- 46, 2000.

JACINTHO, A.C.B.; MIRANDA, A.P.; AMARAL, L.A. Avaliação higiênico-sanitária, teores de nitrato, nitrito e cromo em águas de propriedades rurais e suburbanas em Franca, SP, Brasil. Higiene Alimentar, v.19, n.135, p.92-97, 2005.

LEITE, M.O.; ANDRADE, N.J.; SOUZA, M.R.; FONSECA, L.M.; CERQUEIRA, M.M.O.P.; PENNA, C.F.A.M. Controle de qualidade da água em indústrias de alimentos. Leite \& Derivados, v.69, p.38-45, 2003.

MEDEIROS, M.I.M. Associação de agentes patogênicos isolados em análise microbiológica da água, com a presença de mastite clínica ou subclínica, em propriedades leiteiras da região de Cerqueira César-SP. 2005. 73f. Dissertação (Mestrado em Medicina Veterinária) - Faculdade de Medicina Veterinária e Zootecnia, Universidade Estadual Paulista, Botucatu, 2005.
PICININ, L.C.A. Qualidade do leite e da água de algumas propriedades leiteiras de Minas Gerais. 2003. Dissertação (Mestrado em Medicina Veterinária - Área de Tecnologia e Inspeção de Produtos de Origem Animal) - Universidade Federal de Minas Gerais, Belo Horizonte, 2003.

POLEGATO, E.P.S.; AMARAL, L.A. A qualidade da água na cadeia produtiva do leite: nível de conhecimento do produtor rural. Higiene Alimentar, v.19, n.129, p.15-24, 2005.

RAPINI, L.S.; CERQUEIRA, M.M.O.P.; SOUZA, R.M.B.; SOUZA, M.R.; PENNA, C.F.A.M.. Qualidade microbiológica da água de propriedades leiteiras na região metropolitana de Belo Horizonte - MG. Revista do Instituto de Laticínio Cândido Tostes, v.58, p.95-98, 2003.

RIBEIRO, A.R.; SILVA, J.A.B.; GARINO JUNIOR, F.; COSTA, E.O. Análise microbiológica da qualidade da água utilizada na ordenha em propriedades leiteiras do Estado de São Paulo e Minas Gerais. Napgama, v.3, n.3, p.3-6, 2000 .

ROBINSON, R.K. Microbiologia lactológica. Zaragoza: Acribia, 1987.

ZAR, E.H. Biostatistical analysis. New Jersey: Prentice Hall, 1999.

Recebido em 24/3/08

Aceito em 19/10/09 